Reprod. Nutr. Dévelop., 1988, 28 Suppl. n 1, 83-84

\title{
Distribution spatio-temporelle des populations microbiennes dans un fermenteur semi-continu de type "Rusitec ", en phase d'adaptation
}

\author{
Sylvie PREVOT, J. BOHATIER, J. SENAUD, Meftaha SENHAJI
}

Zoologie et Protistologie, U.A. C.N.R.S. 138,

Complexe scientifique des Cézeaux, B.P. 45, 63170 Aubière, France.

Summary. In a Rusitec fermentor, microorganisms are distributed between 3 different compartments in which they can be counted. During the adaptation time, there was a general decrease in the populations of ciliates and bacteria. Protozoa population decreased less rapidly in the liquid associated to feed and in the solid compartments.

La période d'adaptation conditionnant le fonctionnement ultérieur du Rusitec, nous avons suivi l'évolution des populations microbiennes pendant la $1^{\text {re }}$ semaine après l'inoculation et leur localisation dans les phases liquide sensu stricto $(\mathrm{PL})$, liquide associée à l'aliment ( $\mathrm{PLA}$ ) et solide (PS).

Matériel et méthodes. Quatre fermenteurs du type de celui décrit par Czerkawski et al. (1977) ont été utilisés. L'inoculum provient d'un mouton fistulé conventionnel, recevant une ration journalière de $1,1 \mathrm{~kg}$ de foin de dactyle jeune et $200 \mathrm{~g}$ de luzerne déshydratée, paille et orge agglomérées. Le substrat est de la luzerne broyée (15 g de matière sèche/sac de maille $150 \mu \mathrm{m}$ ). De la salive artificielle, sans apport d'urée ni de $S$, est infusée avec un débit de $0,03 \mathrm{~h}^{-1}$. Les pourcentages des microorganismes de chaque phase à différents moments après alimentation du Rusitec (ici exemple de T1, $5 \mathrm{~h}$ ) ont été calculés soit par dénombrement direct (ciliés) soit par épifluorescence (bactéries) (Prévot et al., 1988). Les variations du taux d'ATP sont estimées par bioluminescence, après extraction au DMSO (Strehler et al., 1952). On définit PLA comme étant le volume de liquide issu du pressage du sac d'aliment, après un lavage par $20 \mathrm{ml}$ de salive (dilution moyenne : 1,78). Les comptages de ciliés sur PS sont estimés en cellules/g de la phase solide ; les valeurs sont ensuite exprimées en cellules $/ \mathrm{ml}$ et une comparaison avec les populations de PL et PLA est alors possible.

Résultats et discussion. Les populations bactériennes, comptées dans PL et PLA (fig. 3 et 1 ), présentent entre le $1^{\mathrm{er}}$ et le $5^{\mathrm{e}}$ jour une diminution globale d'effectif (de 10 à $40 \%$ selon les fermenteurs), mais restent à des taux proches de ceux rencontrés in vivo (entre 1,5 et $8.10^{10}$ cellules $/ \mathrm{ml}$ ). Le cas des ciliés est différent: leur effectif total diminue de façon très importante (fig. 1 à 3 ) et ceci aussi bien dans PL (98\% de baisse) que dans PLA (78\%) et PS (80\%). Les différences constatées entre les 4 fermenteurs dans PS proviennent dans ce cas d'une plus grande hétérogénéité de l'échantillonnage. La disparition dans les trois phases est presque totale pour Epidinium et Eudiplodinium, les genres se maintenant le mieux étant dans l'ordre Dasytricha, /sotricha et Entodinium. La comparaison des effectifs de ciliés dans les différentes phases (fig. 4) montre l'importance croissante de PLA et PS (respectivement 2,5 à $17 \%$ et 1 à $9 \%$ en 

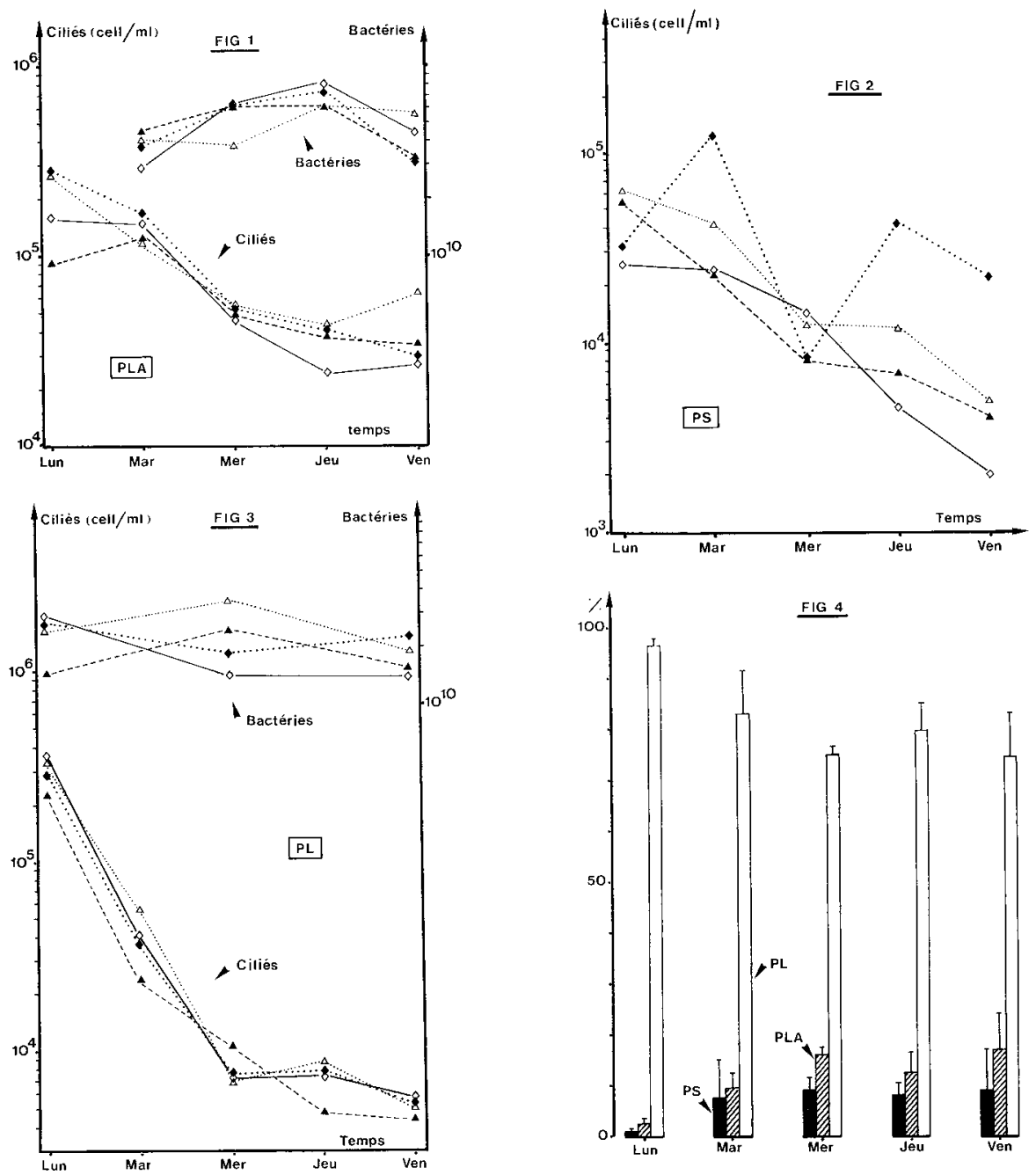

FIG. 1-2-3, - Evolution des populations microbiennes dans les 3 phases 1,5 h après l'alimentation des fermenteurs: $\& \mathrm{~F} 1 \diamond \mathrm{F} 2 \triangle \mathrm{F} 3$ phases (moyenne sur les 4 fermenteurs).

moyenne) par rapport à la phase libre. Les rapports C/ATP (la biomasse C étant estimée d'après les comptages ciliés + bactéries) augmentent fortement pendant la période d'adaptation ( $\times$ 5,5 en moyenne), ce qui traduit une modification de l'état physiologique des cellules, bien que les valeurs de $\mathrm{pH}$ soient comprises entre 6,42 et 7,08 et la concentration moyenne en $\mathrm{N}-\mathrm{NH}_{3}$ supérieure à $200 \mathrm{mg} / \mathrm{l}$. La biomasse $\mathrm{C}$ des protozoaires par rapport à la biomasse totale (ciliés + bactéries) ne représente plus au $5^{\mathrm{e}}$ jour que $2 \%$ dans PL et $10 \%$ dans PLA.

Czerkawski J. W., Breckenridge G., 1977. Br. J. Nutr., 38, 371-384.

Prevot S., Senhaji M., Bohatier J., Senaud J., 1988. Reprod. Nutr. Dev., 28, 137-138.

Strehler B. L., Totter J. R., 1952. Arch. Bioch. Bioph., 40, 28-41. 